\title{
Editorial
}

\section{Ethical issues in limb transplants}

The first successful human hand allograft, performed in Lyon in September 1998 by an international surgical team including one of the authors $(\mathrm{NH})$, was greeted with general admiration in the British press, some scepticism in the French media, and surprising disinterest by medical ethicists. It might be thought, at least by English-speaking readers, that the case is therefore closed. On this basis, hand transplants cross technological frontiers but not ethical ones. They raise no ethical questions that have not been answered long since, in favour of transplantation. There can be no objections except from die-hard opponents of progress in science, according to one of the very few articles in medical ethics to have appeared on the issue of limb transplants, which concludes in favour of cadaveric hand transplantation provided professional, procedural standards of competence have been met (including field strength of the clinical team, scientific background of the innovation, and open public evaluation). ${ }^{1}$

None the less, it is broadly agreed that doctors are not obliged to do everything which is technologically possible. We can stave off the moment of death over and over again in terminally ill patients, but there is a widespread dread of pointless 'high-tech' intervention. Modern medicine tends to generalise the application of technologically innovative procedures beyond their original target group, as epitomised by the widespread overuse of cardiopulmonary resuscitation. ${ }^{23}$ Specifically in transplant surgery, "in every instance, the extension... to organs beyond the original kidney, such as the heart, liver, lungs and pancreas, has raised questions and controversies in the mind of physicians and the general public". ${ }^{4}$ Similarly, a leading professor of transplant surgery has expressed his concerns that "the definition of a suitable cadaver donor has undergone relentless expansion". ${ }^{5}$ All these are problems of what philosophers would call the 'slippery slope' nature. ${ }^{6}$

It might be argued that where a path runs across a slippery slope, it is best avoided in the first place. We do not necessarily advocate that course in this editorial, but we will scout the terrain thoroughly, rather than simply assume that the ethical footing is secure. In transplant surgery, the territory is particularly unfamiliar to many of the settlers. At least one study has identified an 'ethics gap' between the medical and surgical literature: computerised searches of the Medline database reveal a statistically significant difference between the medical and the surgical literatures in their coverage of biomedical ethics. ${ }^{7}$ The landmarks, however, are common to other medical specialties and to applied ethics as a whole. They include the following issues:

- risks and benefits

- patient autonomy and property in the body

- allocation of scarce medical resources

- consent to treatment

- personal identity.

The first person to undergo a successful hand transplant was a 48-year-old New Zealand man who lost his arm 14 years earlier. ${ }^{8}$ The clinical ethics committee on which one of the authors sits (DD) had been asked to approve the limb transplant procedure at St Mary's Hospital in July 1998; but this same planned operation was eventually performed in Lyon that September. While the committee was at pains to state that it found no a priori reasons to consider the procedure unethical, it requested further information on the risks and benefits. Unlike other transplant procedures which may well be life-saving, the benefits of limb transplants do not self-evidently outweigh the risks. The risks of lifelong immunosuppressive medication, and possible development of skin cancer and lymphomas, mean that a limb transplant may possibly shorten life. It has been said of medicine that "the art's most delicate aspect is not to shorten life further, and not to diminish it". ${ }^{9}$ Other innovative transplant procedures, such as multi-organ transplants, may be criticised as having such unacceptably high mortality rates that they are properly characterised as more research than therapy, and possibly non-therapeutic research at that. Both the case of 4-year-old Laura Davies and the two American paediatric cases described by Friedman in a $\mathcal{F} A M A$ editorial ${ }^{4}$ bear out this ethical qualm, with extensive lymphoma at autopsy in the latter cases.

The obvious rejoinder in the case of an adult patient such as the recipient of the Lyon transplant is that it is up to the patient to weigh the risks and benefits. If he chooses to accept the risks, his autonomy deserves respect. This was the ethical position taken by the Lyon transplant team. We accept that argument in other procedures involving self-harm, such as donation of a kidney by a living donor. Respecting patient autonomy, however, is not the same as giving a patient whatever he or she wants. In English law, a patient has no right to demand that a doctor perform euthanasia on her; in the views of at least one prominent ethicist, "My right to die doesn't entail your duty to kill". ${ }^{10}$ It may be wrong to take advantage of another's willingness to harm himself: motives are complex creatures. Following extensive media coverage of a total artificial heart transplantation in 1982, some volunteers were even willing to 'donate' their hearts in the interests of advancing science, though they had no cardiac pathology, ${ }^{11}$ but few surgeons would be willing to operate in those circumstances. In the hand transplant case, the risk is not certain death, and the benefit of the procedure is to the person undertaking the risk; but there may still be a distinction between respecting the patient's 'right' to harm himself and being the agent of possible harm. Nor is it self-evident that people 'own' their bodies and may therefore do what they like with them. Although that may appear just to be common sense, it is not true in English law, and in philosophy it rests on a misconstruction of John Locke's assertion that we have a 'property in our persons', by which Locke meant not our physical bodies but our identity as moral agents. ${ }^{12} 13$

In terms of resource allocation, a patient likewise has no autonomy-based right to demand particular treatments. For nearly 10 years, following the re-amputation of his right forearm after an initial replantation failed, the recipient of the Lyon limb transplant had refused an aesthetic or functional prosthesis. Critics might argue that the ethical questions are similar to those concerning the confirmed smoker on the coronary bypass waiting list who refuses to give an undertaking to stop smoking. Is this the right use of scarce resources? The Lyon operation was performed privately. Should limb transplants be available as treatment on the NHS - particularly when they do not seem to be treatment at all, at least not life-saving treatment? There is no obligation on purchasing authorities to fund even potentially life-saving treatment of an experimental nature, still less elective experimental surgery. 
There are also important issues around consent to treatment. The Lyon patient was asked to sign a detailed consent form and a legal contract, detailing risks in surgery and anaesthesia together with post-surgical risks of possible drug-related complications, malignancies, infections, and long-term psychological complications. The standard for consent in English law is essentially set by what the reasonable doctor would reveal, rather than what the rational patient would want to know (roughly the standard in US law): it is thus not a standard of informed consent as such, which is 'no part of English law'. The surgical team certainly gave this patient enough information by usual professional standards, and indeed more than enough to satisfy the rather minimal requirements of English law. There is an important caveat, however: because limb transplants are an experimental procedure, there is an insufficient body of evidence on the basis of which patients can be informed. The team in Louisville which recently performed the first US hand transplant has chosen to give the patient a reduced dose of immunosuppressive medication: "Because a hand transplant is not a life-saving procedure, the drug treatment will be less aggressive than that of other organ transplants", as one of the team declared. It is not clear whether the patient consented to receive a 'riskier' treatment regime, and if he did, on what evidential basis.

Another difficulty relating to consent lies not with the recipient but with the donor. The NHS Organ Donor Register form reads: "I request that after my death: (tick either) any part of my body, or (tick as applicable) kidneys, heart, liver, corneas, lungs, pancreas may be used for the treatment of others." Potential donors could reasonably assume that the whole is no more than the sum of these parts: that the list of possible organs for donation comprises all the possibilities, and does not mention limb transplants. Whether courts would infer consent to donate a hand from this form remains to be seen, should the issue arise (and that may be unlikely, since it is hard to see who would have standing to sue).

The issue of proxy consent from relatives must also be considered. French law in relation to organ donation is based on the 'opt-out' principle, but in the UK, where the 'opt-in' system applies, consent must have been obtained from donors before their death. The consent or refusal of relatives normally has no formal validity in English law, although a recent study concluded that over half of general practitioners surveyed were unaware of that. However, the Human Tissue Act 1961 requires doctors to consult relatives about organ donation in the absence of consent from the deceased; the position is complex in law, but essentially a spouse or relative has the power of veto. In countries with the 'opt-out' system, it is also customary to request the relatives' permission, although this too carries no legal weight. ${ }^{14}$ Since 1987 US doctors have been required by law to request relatives' permission for 'harvesting' organs of deceased patients who had not given a consent before death. Would most doctors be happy to ask for the dead person's hands? If not, is this because required request is objectionable, or hand transplants are? This leads into the slightly more rarefied and philosophically more complex issues of bodily integrity and personal identity.

Because the transplanted hand - left uncovered from the beginning, for postoperative monitoring - is visible to its recipient, as no other transplanted organ is, limb transplants are not just surgically more complex, but also ethically so. (The visibility of the amputation was also thought to matter to the donor, in some sense: he was fitted with a custom-made aesthetic prosthesis "to restore the normal appearance of the donor in respect to his dignity"). ${ }^{8}$ This difference transcends the so-called 'yuck factor': it is not just a matter of the 'unnaturalness' of hand transplants. All medical intervention is unnatural in that it constitutes interference with the natural order, although it is perfectly natural in the sense that we are ourselves part of that order. ${ }^{15}$ (It may be that the argument from unnaturalness fulfils our need to maintain boundaries against which our choices have value ${ }^{16}$, but this says nothing about where the boundaries should be set.) One argument in favour of xenotransplants has been that all transplants are unnatural, and may affect our sense of bodily integrity, but that our human identity is not wrapped up in any of our organs (with the possible exception of the brain, to which we shall return). "If the essence of humanity is seen as a capacity to transcend their level of organic existence, then a person's sense of identity should not, in theory, be threatened by a transfer of organs across species boundaries", the Nuffield Council Working Party on Xenografts argued. ${ }^{17}$ If this were true of non-human organs, then a fortiori it should be true of any human transplant, whether of kidney, limb, or brain tissue. Yet there are two grounds for doubting whether it is true of human transplants. The first is the empirical evidence from transplant recipients, many of whom do report feeling disturbed at the sense of 'otherness' of part of a dead person's body in their own. ${ }^{18}$ In principle at least, this could be controlled for through psychiatric testing and counselling of recipients.

The more challenging question is philosophical: whether the hand represents personal identity in a way that other organs do not. We want to end with a suggestion that we view as almost as innovative as the surgical procedure of limb transplant itself: despite the fact that the Lyon patient considers the transplanted arm as his own, it is fair to say that the hand represents a sort of halfway house in terms of personal identity, between internal organs and brain tissue. Opponents of brain tissue transplants reject the argument that they are not simply about restoring normal function to the recipient: they also alter the recipient's identity in a profoundly problematic way-so that the person who gave consent to receiving the tissue is no longer the same person after the transplant. ${ }^{120}$ Similarly, we need to consider the wider function of the hand in relation to identity, as an instrument of physical intimacy, of contact with others, of consummate skill in artists and musicians, of agency itself (as witness the use of 'hand' to represent agency in such phrases as 'the hand of Fate', 'by his own hand', 'the hand of God'). The intimacy function of the hand might even, more speculatively, give rise to rights in those with whom the donor and recipient of the transplanted hand have been intimate.

DONNA DICKENSON Leverhulme Senior Lecturer in Medical Ethics and Law, Imperial College
School of Medicine, London, UK NADEY S HAKIM Surgical Director Transplant Unit, St Mary's Hospital, London W2 1NY,

Correspondence to Mr Nadey S Hakim

Accepted 28 April 1999

Keywords: ethics; limb transplants 
1 Siegler M. Ethical issues in innovative surgery: should we attempt a cadaveric hand transplantation in a human subject? Transplant Proc 1998;30:2779-82.

2 Hilberman M, Kutner J, Parsons D, Murphy DJ. Marginally effective medical care: ethical analysis of issues in cardiopulmonary resuscitation (CPR). $\mathcal{F}$ Med Ethics 1997;23:361-7.

3 Bruce-Jones PNE. Resuscitation decisions in the elderly: a discussion of Bruce-Jones PNE. Resuscitation decisions in
current thinking. F Med Ethics 1997;22:286-91.

4 Friedman E. The desperate case: CARE (costs, applicability, research, eth4 Friedman E. The desperate case: CARE (cost
ics) (Editorial). $7 A M A 1989 ; 261: 1483-90$

ics) (Editorial). FAMA 1989;261:1483-90.
Bollinger RR. Ethics of transplantation. In: Hakim NS, Danovitch G, eds. Bollinger RR. Ethics of transplantation. In: Hakim NS, Danovitch G,
Contemporary transplantation. London: Springer Verlag, 2000; in press.

Contemporary transplantation. London: Springer Verlag, 2000; in press.
Williams B. Which slopes are slippery? In: Lockwood M, ed. Moral dilemmas in modern medicine. Oxford: Oxford University Press, 1985; pp 126-37.

7 Paola F. Barten SS. An 'ethics gap' in writing about bioethics: a quantitative comparison of the medical and the surgical literature. F Med Ethics 1995;21: 84-8.

8 Dubernard JM, Owen E, Herzberg G, et al. Hand transplant: 6 months report. Lancet 1999;353:1315-20.

9 Elliott C. Doing harm, living organ donors, clinical research, and The Tenth Man. F Med Ethics 1995;21:91-6.

10 Callahan D. Can we return death to disease? In: Campbell CS, Crigge BJ, eds. Mercy, murder and morality: perspective on euthanasia. Briarcliff Manor, New York: Hastings Center, 1989.
11 Shaw M, ed. After Barney Clark: reflections on the Utah artificial heart program. Austin, TX: University of Texas Press, 1984.

12 Dickenson D. Property. Women and politics. Cambridge: Polity Press, 1997; p 78.

13 Waldron J. The right to private property. Oxford: Clarendon Press, 1988; $\mathrm{p}$ 179

14 Haag BW, Stuart FP. The organ donor: brain death, selection criteria, supply and demand. In: Flye MW, ed. Principles of organ transplantation. Philadelphia: WB Saunders Co, 1989; p 185.

15 Hughes J. Xenografting: ethical issues. $\mathcal{F}$ Med Ethics 1998;24:18-24.

16 Norman R. Interfering with nature. F Appl Philosophy 1996;13:1-11.

17 Nuffield Council on Bioethics. Animal-to-human transplants: the ethics of xenotransplantation. London: Nuffield Council, 1996; p 104.

18 Craven J, Rodin GM. Psychiatric aspects of organ transplantation. New York: Oxford University Press, 1992; pp 169-71.

19 Northoff G. Do brain tissue transplants alter personal identity? Inadequacies of some 'standard arguments'. F Med Ethics 1996;22:174-80.

20 Burd L, Gregory JM, Kerbeshian J. The brain-mind quality: ethical issues in the use of human brain tissue for therapeutic and scientific purposes. $\mathcal{F} \mathrm{Med}$ Ethics 1998;24:118-22. 